\title{
Management of extracranial arteriovenous malformations of the head and neck
}

\section{Fernández-Alvarez, Veronica}

2020-04

Fernández-Alvarez , V , Suárez, C , de Bree , R , Nixon , I J Mäkitie , A A, Rinaldo , A , Downer , J \& Ferlito , A 2020 , ' Management of extracranial arteriovenous malformations of the head and neck ' , Auris-nasus-larynx. , vol. 47 , no. 2 , pp. 181-190 . https://doi.org/10.1016/j.anl.2019.11.008

http://hdl.handle.net/10138/323371

https://doi.org/10.1016/j.anl.2019.11.008

acceptedVersion

Downloaded from Helda, University of Helsinki institutional repository.

This is an electronic reprint of the original article.

This reprint may differ from the original in pagination and typographic detail.

Please cite the original version. 


\title{
Management of extracranial arteriovenous malformations of the head and neck
}

\author{
Veronica Fernández-Alvarez ${ }^{\mathrm{a}, *}$, Carlos Suárez ${ }^{\mathrm{b}, \mathrm{c}}$, Remco de Bree ${ }^{\mathrm{d}}$, Iain J. Nixon ${ }^{\mathrm{e}}$, \\ Antti A. Mäkitie ${ }^{\mathrm{f}, \mathrm{g}, \mathrm{h}}$, Alessandra Rinaldo ${ }^{\mathrm{i}}$, Jonathan Downer ${ }^{\mathrm{j}}$, Alfio Ferlito ${ }^{\mathrm{k}}$ \\ ${ }^{a}$ Vascular Surgery Department, Hospital Torrecárdenas, Almería, Spain \\ ${ }^{\mathrm{b}}$ Instituto de Investigación Sanitaria del Principado de Asturias and CIBERONC, ISCIII, Oviedo, Spain \\ ${ }^{\mathrm{c}}$ Instituto Universitario de Oncología del Principado de Asturias, University of Oviedo, Oviedo, Spain \\ ${ }^{\mathrm{d}}$ Department of Head and Neck Surgical Oncology, UMC Utrecht Cancer Center, University Medical Center Utrecht, Utrecht, The \\ Netherlands \\ ${ }^{\mathrm{e}}$ Departments of Surgery and Otolaryngology, Head and Neck Surgery, Edinburgh University, Edinburgh, UK \\ ${ }^{\mathrm{f}}$ Department of Otorhinolaryngology - Head and Neck Surgery, University of Helsinki and Helsinki University Hospital, Helsinki, \\ Finland \\ ${ }^{g}$ Research Programme in Systems Oncology, Faculty of Medicine, University of Helsinki, Helsinki, Finland \\ ${ }^{\mathrm{h}}$ Division of Ear, Nose and Throat Diseases, Department of Clinical Sciences, Intervention and Technology, Karolinska Institutet and \\ Karolinska Hospital, Stockholm, Sweden \\ ${ }^{\mathrm{i}}$ University of Udine School of Medicine, Udine, Italy \\ ${ }^{\mathrm{j}}$ Department of Clinical Neurosciences, Edinburgh University, UK \\ ${ }^{\mathrm{k}}$ Coordinator of the International Head and Neck Scientific Group, Italy
}

A R T I C L E I N F O

\section{Article history:}

Received 26 August 2019

Accepted 2 December 2019

Available online $\mathrm{xxx}$

\section{Keywords:}

Congenital vascular anomaly

Arteriovenous malformation

High-flow vascular malformation

Hemangioma

Superselective embolization

\section{A B S T R A C T}

The purpose of this study was to review the outcomes of the different therapies for extracranial head and neck arteriovenous malformations (AVMs).

AVMs are high-flow congenital vascular anomalies. They are composed of a complex system of vessels directly connecting feeding arteries to draining veins forming a nidus.

They may be potentially life-threatening due to progressive symptoms and infiltrative disease. Extracranial AVMs most commonly affect the head and neck area (47.4\%) followed by the extremities (28.5\%). AVMs are best characterized as being either focal or diffuse. Focal AVMs have good outcomes following adequate treatment. Diffuse lesions have multiple feeding vessel, which results in high rates of recurrence despite treatment.

The management of AVMs includes conventional surgery and endovascular techniques. A combination of embolization and surgical resection has become the treatment of choice over the last years. The main goal of both forms of treatment being the complete blockage or resection of the nidus. Transcatheter embolization of vessels has evolved over the years and new embolic agents have emerged. The types of materials available for embolization are classified into mechanical devices, liquid agents and particulates. Efficacy, rate of recurrence and most common complications were evaluated.

AVMs recurrence after embolization or resection is reported in up to $80 \%$ of cases. Incomplete resection and embolization can induce aggressive growth of the remaining nidus and the risk of progression is up to $50 \%$ within the first 5 years and recurrences can occur up to 10 years later.

\footnotetext{
This article was written by members and invitees of the International Head and Neck Scientific Group (www.IHNSG.com).

* Corresponding author.

E-mail address: U072421@uniovi.es (V. Fernández-Alvarez).
} 
Although ethanol seems to be associated with the highest degree of cure and permanent occlusion, the overall complication rate reported was $48 \%$. Other materials, such as cyanoacrylate, have obtained modest rates of complete remission, while the reported rates of complete regression of AVMs with Fibrin glue and Polyvinyl alcohol are above 50\%. At present, there are no unified agreement on the ideal embolic agent.

Therefore, a multidisciplinary approach is recommended to support decision making about the best therapeutic approach and to achieve optimal outcome. A long-term post-treatment follow-up is recommended to recognize early recurrence.

(C) 2019 Oto-Rhino-Laryngological Society of Japan Inc. Published by Elsevier B.V. All rights reserved.

\section{Introduction}

Vascular malformations are rare vascular anomalies composed of inappropriately connected vasculature. Any blood vessel type, or a combination of them, can be affected in a vascular malformation.

Mulliken and Glowacki first proposed a classification of vascular anomalies in 1982 based on histology. This classification was accepted by the International Society for the Study of Vascular Anomalies (ISSVA) in 1992. Vascular anomalies were divided into tumors, like hemangiomas (caused by an endothelial cell proliferation) and vascular malformations (caused by a development of abnormal vascular channels). The most common vascular malformations include lymphatic malformations (LMs), capillary-venular malformations (CMs), venous malformations (VMs) and arteriovenous malformations (AVMs). Furthermore, they were subdivided based on the flow characteristics into high-flow (AVMs) and lowflow lesions (LMs, CMs and VMs) [1].

Arteriovenous malformations (AVMs) of the head and neck are high-flow congenital vascular anomalies. They are composed of a complex system of vessels directly connecting feeding arteries to draining veins forming a nidus. The normal capillary network is lacked. AVMs are considered as the most dangerous subtype of vascular malformation because they may be potentially life-threatening attributing to progressive symptoms and infiltrative disease [2,3]. They have diverse clinical presentations and are complex to manage due to high rates of recurrence irrespective of therapeutic approach. The classification and management of AVMs have considerably changed in the last few years. Endovascular treatment is currently almost always part of the treatment of AVMs often combined with surgical resection. However, in many cases, treatment is only palliative [4]. A multidisciplinary approach is recommended for optimization of patient outcomes, especially in pediatric AVMs in which treatment and timing of intervention must be individualized [5].

\section{Epidemiology}

The prevalence of AVM is not well known but in hospitalbased autopsy data it ranges from 5 to $613 / 100,000$ [6]. They are uncommon vascular malformations representing only $1.5 \%$ of all vascular anomalies [4,7]. Over $90 \%$ of
AVMs occur intracranially [8]. Although the exact incidence is unknown, Visser et al. have shown that extracranial AVMs were present in only $4.7 \%$ of the 1131 patients with vascular anomalies referred to their Vascular Anomalies centre over a 14-year period [9]. Extracranial AVMs most commonly affect the head and neck area $(47.4 \%)$ followed by the extremities (28.5\%) [10]. It has been reported that $50 \%$ of the head and neck AVMs affect the oral and maxillofacial region $[4,7]$. In a retrospective review of 81 patients with an AVM of the head and neck, Kim et al. reported that cheek was the most common site (31\%) followed by ear (16\%) [11]. Race or sex predilection has not been demonstrated, [5,12] although Spreafico et al. have reported a male:female ratio of $1: 1.5$ [13].

\section{Classification}

AVMs are best characterized as being either focal or diffuse. Focal AVMs appear as a soft tissue mass usually diagnosed during infancy or childhood. They have a single arterial feeder and well-defined borders and a nidus. Focal AVMs have good outcomes following adequate treatment. In contrast, diffuse AVMs cross and usually destroy tissue boundaries. They are more frequently discovered in older children and adults. Diffuse lesions have multiple feeding vessels that make successful treatment more challenging, requiring vigilant follow-up and repeated interventions [5,3,14,15].

The Schobinger classification is the most used system for clinical AVM characterization according to their natural course of progressive disease Table 1. It was introduced at the International Society for the Study of Vascular Anomalies (ISSVA) meeting in 1990 [16].

AVMs have also been staged based upon disease quiescence (stage I), active or palpable growth (stage II), soft tissue destruction (stage III) or associated heart failure (stage IV). Due to the variability of the disease, further modifications were proposed by Richter and Suen to include the number of cervicofacial subunits involved and depth of invasion [17].

\section{Natural history and clinical features}

AVMs are detected at birth in $40 \%$ of cases [18]. They can be identified as a hypervascular blush and are often misdiagnosed as birthmarks or "hemangiomas". However, unlike hemangiomas, AVMs are typically progressive, and sponta- 
neous regression is extremely rare. To date there have been no reported cases of spontaneous regression of AVMs. Hemangiomas are usually not present at birth and generally appear suddenly during the early neonatal period as a rapidly growing tumor. Hemangiomas show an initial rapid growth during the early proliferate phase followed by slow regression through the long involution phase, generally resolving spontaneously before reaching the age of 7-9 years.

Although these lesions are congenital, they usually grow during adolescence and become clinically apparent in adulthood. Liu et al. have demonstrated that the average age at which AVMs progresses is 12.7 years $(+/-11$ years) [15].

The trigger for their expansion is still not completely understood. Hormonal changes (puberty, pregnancy and hormone therapy), trauma, infection, or iatrogenic causes (biopsies, surgery, embolization) are considered potential growth triggers that stimulate progression and aggravate morbidity [19]. However, Liu et al. did not find progression in pregnant mothers with quiescent lesions [15].

On physical examination, AVMs may show local erythema and hyperthermia with prominent pulsations, a palpable thrill and an audible bruit [20]. It is important to understand that the arteriovenous shunting that characterizes AVMs may have significant hemodynamic impact, often leading to reduced capillary oxygenation, ischemia, local hypervascularity, vascular steal phenomenon and increased venous pressure. These can result in destruction of soft and bony tissue, pain, ulceration, gangrene, dangerous hemorrhage, esthetic deformity and functional deficits when the malformation reaches a significant size. Though uncommon, congestive heart failure is also a possible complication of AVMs.

\section{Etiology and pathogenesis}

The etiology and pathogenesis of AVMs remain unclear although they are suggested to result from a disturbance in vascular development during the 4-6th weeks of gestation [16]. This is thought to be caused by a failure of the arteriovenous channels to undergo apoptosis or to regress in the primitive retiform plexus. These nonfunctioning shunts are later canalized to form small arteriovenous connections that dilate, cause local ischemia, and subsequently enter a cycle of vascular collateralization and recruitment.

Studies of cerebral AVMs have identified the involvement of the vascular endothelial growth factor (VEGF) and plateletderived growth factor (PDGF). However, it is unclear if pathophysiological mechanisms for cerebral and extracranial AVMs are identical [21]. Increased levels of factors involved in vascular destabilization, such as angiopoeitin-2 and matrix metalloproteinase- 9 , and reduced levels of vascular stabilizers (angiopoeitin-1, integrin, and metalloproteinase inhibitors) have also been found in AVMs [22,5]. AVMs are usually isolated findings, however, a genetic predisposition for AVMs can be found in several clinical syndromes, such as hereditary hemorrhagic telangiectasia (HHT, mutations in ENG, ACVRL1 and SMAD4 genes affecting the TGF-beta signaling pathway), capillary-malformation-arteriovenous malformation
Table 1

Schobinger classification.

$\begin{array}{ll}\text { Stage I } & \text { Quiescence. } \\ & \text { Asymptomatic. Cutaneous pink blush, warmth } \\ \text { Stage II } & \text { Expansion. Active growth. } \\ & \text { Same as stage I plus enlargement, pulsations, thrill, bruit } \\ & \text { and tortuous veins } \\ \text { Stage III } & \text { Destruction. } \\ & \text { Same as stage II plus either dystrophic skin changes, } \\ & \text { ulceration, tissue necrosis, persistent pain, bleeding, } \\ & \text { disfigurement } \\ \text { Decompensation. } & \text { Same as stage III plus cardiac failure }\end{array}$

Table 2

Magnetic resonance appearance of major vascular anomalies.

\begin{tabular}{lll}
\hline & High Enhancement & Low Enhancement \\
\hline Intermediate T2 signal & Hemangioma & AVM \\
High T2 signal & VM & LM \\
\hline
\end{tabular}

(CM-AVM, mutation in RASA1 gene), CLOVES syndrome (somatic mutation in PIK3CA) and PTEN hamartoma tumor syndrome (mutation in PTEN gene) $[18,23]$.

\section{Diagnosis}

AVM diagnosis is clinical and based on history and physical examination with additional imaging characteristics. In general, spontaneous, nontraumatic bleeding from a vascular anomaly in an older child suggests the presence of an AVM [5]

\subsection{Pathology}

AVMs' histology reveals numerous arteriovenous shunts and dilated capillary beds with a combination of loosely grouped capillaries, arterioles, and venules within a fibromyxomatous background. The vessels are typically tortuous, are deficient in smooth muscle and have poor interendothelial junctions. AVMs are characterized by thick-walled arteries and arterialized thick-walled veins, which have the inherent potential to grow and recruit new blood vessels [23].

\subsection{Imaging}

Radiological imaging confirms the diagnosis, maps the lesion, shows the possibilities and route of endovascular treatment, identifies associated anomalies and provides surveillance of disease and response to therapy. Table 2 shows a simplified MRI-based diagnostic algorithm that can be used to differentiate between the most common vascular lesions Table 2. Table 3 summarizes the imaging features of hemangioma and AVM Table 3. [24].

Ultrasonography with color Doppler is widely available and useful in evaluating the clinical suspicion of an AVM if accessible and it can be used as an inexpensive modality to assess disease progression and treatment outcomes. Doppler ultrasonography images show a network of multiple arteries 
Table 3

Imaging features of hemangioma and AVM.

\begin{tabular}{lll}
\hline $\begin{array}{l}\text { Imaging } \\
\text { Features }\end{array}$ & AVM & Hemangioma \\
\hline US & $\begin{array}{l}\text { High-velocity low-resistance arterial flow and pulsatile flow } \\
\text { in venous drainage } \\
\text { Enlarged feeding and draining vessels } \\
\text { Osseous overgrowth }\end{array}$ & Multilobular mass with distinct margins \\
CT & Enlarged feeding and draining vessels & Hypervascular with large internal and feeding and draining \\
Tissue is permeated by vascular flow voids & vessels \\
MRI & Mild enhancement and T2 hyperintensity reflect tissue & Proliferative phase: \\
& edema & $\begin{array}{l}\text { Avid enhancement and only moderate T2 hyperintensity } \\
\text { reflecting hypercellularity on MRI Involuting phase: }\end{array}$ \\
& & $\begin{array}{l}\text { Progressive diminution in enhancement with increasing } \\
\text { fatty component }\end{array}$ \\
\hline
\end{tabular}

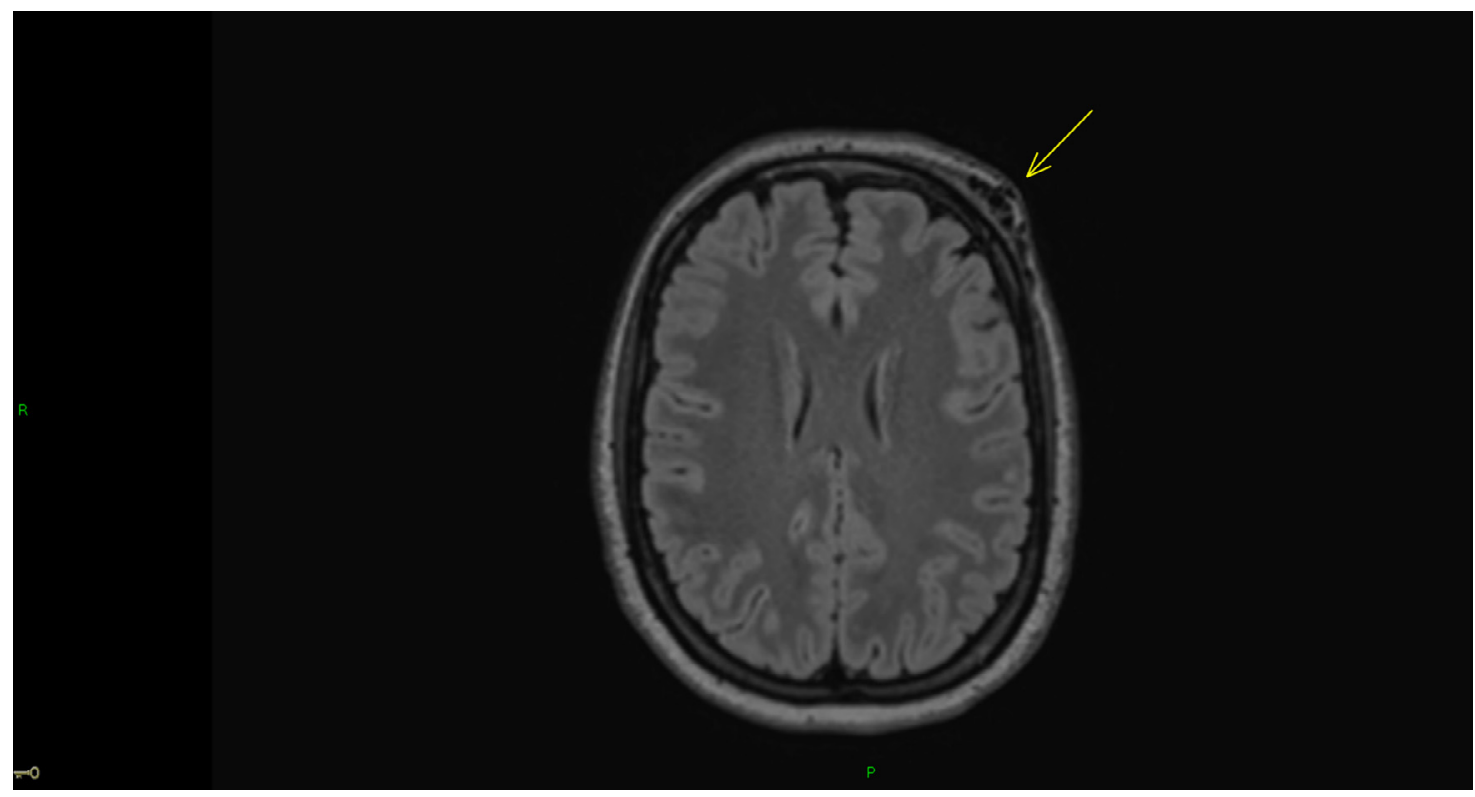

Figure 1. Axial reconstruction from FLAIR volume MRI showing characteristic subcutaneous flow voids of a left forehead AVM.

with increased diastolic flow, dilated blood vessels and arterialized draining with a biphasic waveform.

Computed tomography angiography (CTA) and magnetic resonance angiography (MRA) define the morphology, nidus, and supportive vasculature of AVMs more accurately than other modalities and is less invasive than conventional angiography. CTA is important for delineating bone involvement (overgrowth and/or lysis). However, repeated CTAs add unwanted radiation exposure in the pediatric population. On angiography AVMs appear as multiple, enlarged, enhancing, feeding arteries filling a cluster of grapelike structures corresponding to the nidus with rapid contrast shunting from feeding arteries to draining veins.

MRA may delineate the lesion better than CT because it provides superior tissue contrast resolution. AVMs characteristically appear as enlarged vascular channels, with dilated feeding and draining vessels and no discrete soft-tissue mass. These high-flow vessels have bright signal intensity in flowenhanced gradient echo images and appear as multiple flow voids in T2-weighted spin echo sequence (Fig. 1).

Digital Subtraction Angiography (DSA) is the gold standard for diagnosis and characterization of an AVM because it provides the best spatial and temporal resolution to study vascular anatomy. DSA is an invasive procedure that should be considered only for treatment planning. The classic angiographic appearance of an AVM consists of multiple enlarged feeding arteries rapidly shunting into a nidus and then into dilated draining veins. A superselective catheterization helps to delineate the feeding vessels and the nidus.

\section{Management}

The treatment of AVMs remains challenging especially in diffuse lesions, which results in high rates of recurrence despite treatment. The current management of AVMs includes conventional surgery and endovascular techniques, with the main goal of both forms of treatment being the complete resection or the complete block of the nidus. Partial treatment can induce aggressive growth of the remaining nidus leading to worsening disease $[5,8,16]$.

Based on nidal morphology and in order to provide better guidance, Cho et al. proposed an angiographic classification system for a therapeutic approach to AVMs, which provides predictive information in terms of clinical outcome [25]. According to their work AVMs were divided into four subtypes Table 4. As reported by Cho et al., type I and type II malformations were the most curable lesions. Types IIIa and IIIb 
Table 4

Angiography classification system of AVM.

\begin{tabular}{lll}
\hline Type I & $\begin{array}{c}\text { Arteriovenous } \\
\text { fistulae }\end{array}$ & $\begin{array}{c}\text { Three or less arteries shunting to } \\
\text { one draining vein }\end{array}$ \\
Type II & $\begin{array}{c}\text { Arteriolovenous } \\
\text { fistulae }\end{array}$ & $\begin{array}{c}\text { Multiple arteries shunting to one } \\
\text { draining vein }\end{array}$ \\
Type III & Arteriolovenulous & $\begin{array}{c}\text { Multiple arteries shunting to } \\
\text { multiple veins }\end{array}$ \\
Type IIIa & & $\begin{array}{c}\text { - with nondilated fistula } \\
\text { Type IIIb }\end{array}$ \\
\hline
\end{tabular}

were more difficult to treat and prone to higher failure and recurrence rates.

Surgical treatment of AVM in the head and neck, especially in the upper aerodigestive tract, is particularly difficult because of the complex anatomy of the region. Surgical ligation or embolization of the proximal arteries should not be performed because the lesion will develop collateral arterial feeders that will make endovascular treatment of the lesion more difficult and also the obliteration of these arteries can block further embolizations [16,20]. Success of selective embolization depends on local vascular anatomy and chance of collateralization. However, this is often unsuccessful as a single treatment method for these high-flow lesions since recruitment of arteries from surrounding tissue is likely to occur. In these cases, maximum safe embolization followed by direct (or short-term) surgical resection is the recommended treatment. However, this treatment strategy may be associated with serious complications and extensive morbidity and negative impact on quality of life.

A combination of embolization and surgical resection has become the treatment of choice over the last years.

\subsection{Surgery}

Surgery should aim for complete resection of the nidus, minimizing functional loss and preservation of aesthetics. In the past, surgical monotherapy of AVMs was more popular than interventional therapy or combined therapy [20]. Nowadays, surgical resection is a good choice for localized AVMs, in which complete removal can be performed with minimal surgical bleeding and well-defined borders [8]. Preoperative superselective embolization of the lesion is recommended and should be performed 24-48 h prior to surgery. This approach helps to minimize intraoperative bleeding. Nonstick bipolar cautery and gel foam with thrombin are important intraoperative tools to control bleeding. Lastly, immediate reconstruction may be necessary which may require local, regional, or microvascular free flaps. The recurrence rate after microvascular free flap reconstruction may be low, because highly vascularized free flaps may regulate and even reverse postoperative changes in the vascularization and fibrosis of the surgically treated area potentially leading to an ischemic environment which would facilitate the development of neovasculature by means of sprouting and non-sprouting angiogenesis. A microvascular free flap may stabilize hemodynamics surrounding the AVM by interrupting the vicious cycle of ischemia [25]. Patients with AVMs that are difficult to delineate by

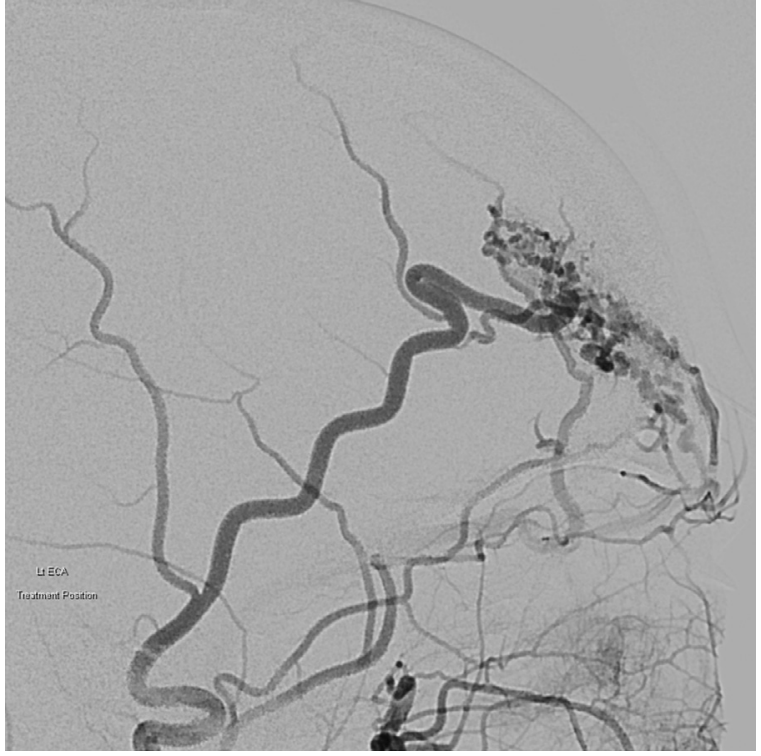

Figure 2. Left ECA angiogram showing an extracranial AVM nidus fed primarily by the superficial temporal artery.

imaging are not good candidates for resection and should be considered for alternative therapies.

\subsection{Endovascular treatment}

Endovascular treatment can be performed using a transarterial approach, direct percutaneous puncture of the nidus, or a retrograde transvenous approach. Cho et al. reported that type II and type IIIb lesions had better results with transvenous approach or direct puncture while type IIIa lesions were usually only reachable by a transarterial approach [26]. However, Davos et al. and also Meila et al. preferred the transarterial route as the first choice although in cases with severe tortuosity or proximal occlusion from prior embolization or surgical procedures, they performed direct puncture [27,28] (Figs. 2-5)

Intravascular embolization of AVMs can be used as a single modality therapy with a success rate of about $65 \%$ for complete closure of extracranial AVMs. Extremely large or diffuse AVMs with great risk of surgical morbidity are also reasonable candidates for embolization alone [5]. In addition, embolization alone can be considered as palliation for temporary disease control. AVM is not a static lesion clinically, it progresses over time [15]. As a result of that, several sessions of embolization may be required to provide therapeutic effect on AVMs [23,26,28]. Le Fourn et al. performed 66 embolizations in 31 patients reaching devascularization rate greater than $75 \%$ of the initial levels in $56.3 \%$ of the patients, as well as symptomatic improvement in $72 \%$. For 13 AVMs that required 2 or more embolizations, the mean interval between procedures was $18.7+/-28.5$ months (median: 7.5 months) [29]. Meila performed 86 embolizations with a mean number of procedures of 6.1 per patient reaching a complete angiographically confirmed closure of the AVM in $60 \%$ of the patients [28]. On the other hand, Liu et al. reported in a study with 272 patients that the rate of recurrence was 14.2 times greater in patients undergoing embolization 


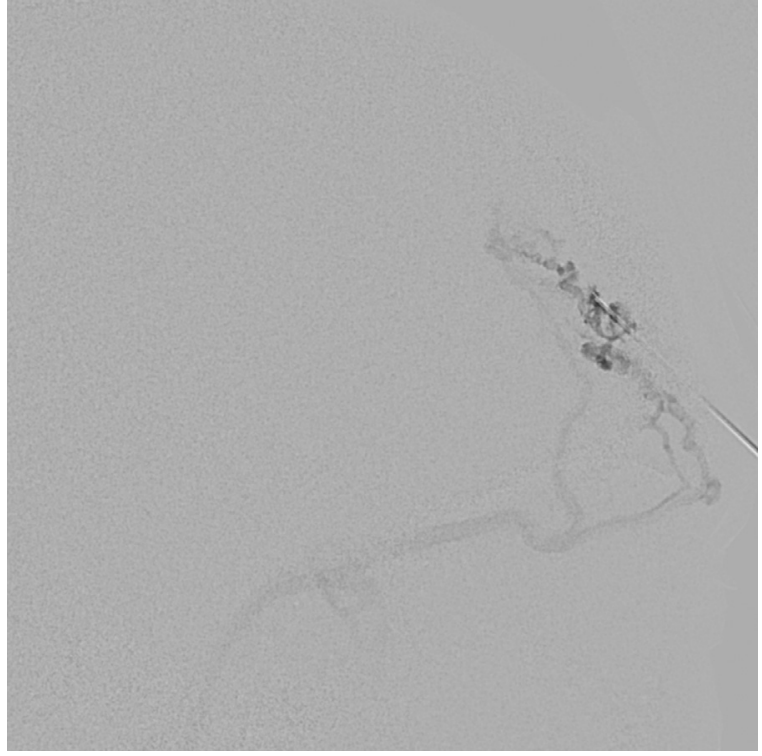

Figure 3. Angiographic injection confirming intranidal needle position after direct percutaneous placement under ultrasound guidance.

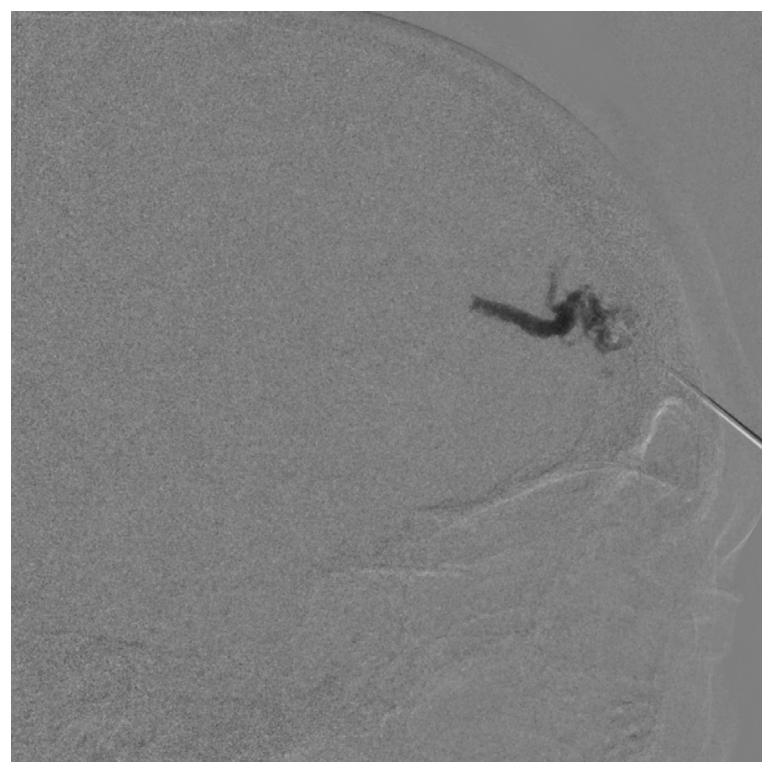

Figure 4. Direct percutaneous injection of PHIL 25\% liquid embolic under fluoroscopic roadmap visualization.

alone versus resection (with or without embolization). Unfortunately, multiple embolizations have not yet been shown to lower the rate of recurrence. In fact, Liu et al. demonstrated that repeated embolization did not reduce the recurrence rate, which was $97.7 \%$ after a single treatment, $98.2 \%$ after two embolizations and $99.1 \%$ following three or more treatments. Similarly, the recurrence rate was not reduced after multiple resections (with or without embolization) [15]. However, in a few children with diffuse and expanding disease, serial embolizations (every 3 months) has been effective to control deep lesions [5]. Additionally embolization can replace a disfiguring pulsatile lump with a lump of embolic agent. So even if complete nidal occlusion is achieved, surgical resection may be preferred to optimize cosmetic result

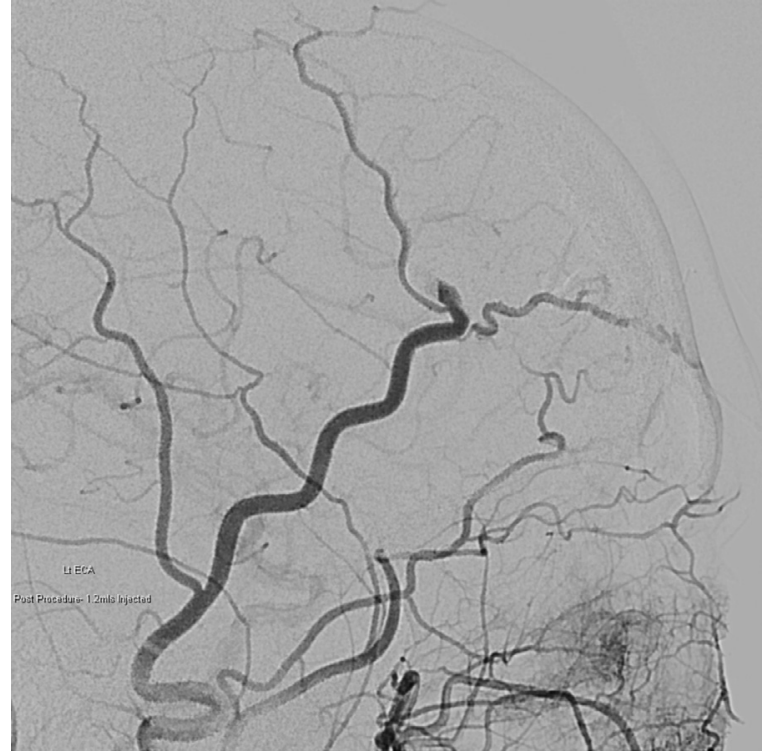

Figure 5. Final left ECA angiogram showing complete nidal occlusion following liquid embolic embolization.

and eliminate risk of recurrence. If left in situ, particularly around buccal mucosa erosion and ulceration can occur over time exposing subcutaneous embolic agent. Surgical resection following embolization can help prevent this.

The types of materials available for embolization are classified into mechanical devices (coils), liquid agents (absolute ethanol, n-butyl cyanoacrylate, ethylene-vinyl alcohol copolymer, precipitation hydrophobic inyectable liquid and fibrin glue) and particulates (polyvinyl alcohol).

Transcatheter embolization of vessels has evolved over the years and new embolic agents have emerged. Embolization consists of intravascular injection of an inert agent, in order to occlude blood flow. A successful embolization requires occlusion of the nidus of the AVM, sparing the normal arterial branches supplying adjacent areas. An arteriogram is initially performed to delineate the vessel selected to be embolized. A wide variety of catheters with different shapes are useful for gaining access to the nidus. The microcatheter is advanced to a location as close to the nidus as possible. Then the coil, or liquid embolic agent can be introduced under fluoroscopy to ensure accurate deployment. A postembolization arteriogram should be performed through the catheter or sheath to exclude residual feeding vessels. If heparin was administered before embolization, then complete vessel occlusion may not be immediately seen on the final images.

Embolization is stopped by considering the duration of the procedure, the local side effects and the volume of the embolic agent injected. The decision to perform a new embolization is linked to the clinical efficacy of the treatment, the recurrence of symptoms, the technical difficulties of a new embolization and the possibility of surgical excision $[23,26,29]$

Flow reduction techniques can be used to increase the concentration of the embolic agent within the AVM nidus. This can be performed using balloon catheters to temporarily occlude the arterial inflow or venous outflow. For some le- 
sions external compression during the procedure may be feasible.

\subsubsection{Coils}

Vascular coils consist of a metallic device to occlude blood vessels. Multiple different configurations of coils are available. The diameter of the coil should be oversized by $10 \%-$ $20 \%$ of the vessel diameter to prevent distal migration after placement which is the major complication. If the coil is undersized, it will be free floating when placed in the artery.

The coil is radiopaque and can be visualized well using fluoroscopy. An angiographic catheter is placed at the site intended for coil placement. A guidewire tip is used to advance the coil through the catheter. Under fluoroscopic visualization, the delivery wire is advanced until the entire length of the coil exits the distal end of the catheter. Immediately upon exiting the catheter, the coil begins to twist.

Usually, multiple coils are often necessary. As the coils are being placed, the tip of the catheter may be used to tamp down or to bunch up to compact the coils. This helps to create a good plug to serve as a nidus for thrombus formation and occlusion.

After coil placement is complete, a completion arteriogram is performed to check out an adequate vessel occlusion.

Habitually coils are used in large calibre high flow components or fistulous parts of an AVM nidus. They can be used before liquid embolic agents such as Onyx to reduce flow or to provide plug formation of the dominant feeding branch like inferior alveolar artery or internal maxillary artery in cases of mandibular AVMs [13,27,30].

\subsubsection{Absolute ethanol}

Alcohol has historically been the primary agent used extracranially and therefore, it is one of the agents most often used for embolization of peripheral AVMs [18]. For small AVMs, which are fed by only one or two main arteries, a successful outcome is possible with superselective embolization of the nidus. The most common complications reported with alcohol include skin and peripheral nerve injury. Less common complications include cardiopulmonary collapse, end-organ damage, and renal failure [31]. Sclerosant dilution, misdirection and nontarget effect are common difficulties because high-flow and collateral flow of AVMs may dilute and redirect the ethanol, preventing it from acting in the targeted area for sufficient time to ensure optimal action [23]. The maximum recommend volume is $1.0 \mathrm{~mL} / \mathrm{kg}$, however Mason and colleagues suggested the dose should be reduced to $0.5 \mathrm{~mL} / \mathrm{kg}$ given the increased serum alcohol levels and potential negative side effects.

In a retrospective review of absolute alcohol use in soft tissue AVMs involving a series of 32 patients (142 total sessions), Shin et al. concluded that dose limitations of less than $0.5-1 \mathrm{mg} / \mathrm{kg}$ and a maximum dose per injection of $10 \mathrm{~mL}$ do not cause an overall increase in pulmonary artery pressure [32].

In a series of 66 AVMs, Cho et al. found alcohol most effective for type II (85\%), and type IIIb (83\%) than for type IIIa or mixed types $(50 \%)$. They considered that ethanol embolization was effective in $74 \%$ (32\% cured and $42 \%$ with partial remission). The overall complication rate was $48 \%$ [26]. Su et al. reported comparable results with $84 \%$ of patients effectively controlled with $100 \%$ of the AVMs being devascularized after absolute ethanol embolization with a minor complication rate of $24 \%$ [33]. Park et al. reported a series of 176 patients treated with ethanol embolization. Overall, 68 patients $(39 \%)$ were cured, 91 patients $(52 \%)$ showed a partial response, 9 patients $(5 \%)$ showed no response, treatment failed (in terms of a inaccessible lesion, terminated treatment schedule as a result of an expected complication or no therapeutic effect despite treatment) in 7 patients (4\%), and treatment aggravated the condition in one patient $(1 \%)$. The overall complication rate was $45 \%$ with a $35 \%$ rate of minor complications and $10 \%$ rate of major complications [34]. Lower cure rates were reported by Do et al. in a series of extremity AVMs involving bone. Forty patients with inoperable AVMs in the body and extremities underwent staged ethanol embolizations and it was considered effective in $68 \%$ patients $(40 \%$ cured and $28 \%$ with partial remission). Fifteen percent of procedures resulted in minor complications (skin and transient peripheral nerve injuries) and 3\% resulted in major complications [35].

Dabus et al. concluded that of all embolic agents, ethanol seems to be associated with the highest degree of cure and permanent occlusion. However, owing to its known complications, it should be used by physicians experienced in the use of this agent [27]. Many interventionalists find alcohol to have great risks, including injury to adjacent normal tissues, particularly mucosal surfaces, skin and neurologic tissue, with the potential for cardiopulmonary collapse caused by escape to the right side of the heart and pulmonary bed.

\subsubsection{Cyanoacrylate}

$\mathrm{N}$-butyl cyanoacrylate (n-BCA) belongs to a group of adhesive glues. In the presence of blood, it polymerizes and forms a cast, which adheres to the vessel wall. Cyanoacrylate is a clear substance, so it needs to be mixed with Lipiodol to provide radio-opacity during fluoroscopic injection. The amount of Lipiodol mixed with the n-BCA controls the rate of polymerization. Therefore, the dilution ratio is determined by rate of blood flow and by the depth to which penetration of glue is desired. To prevent polymerization within the catheter, $5 \%$ dextrose in water (D5W) is infused before the injection. The use of a coaxial catheter system is highly recommended to allow for a more secure catheter position. Also, in case of glue around the microcatheter tip, maneuvers to release it are easier and safer to perform. To inject the glue a three-way stopcock can be used to allow flushing of the catheter with D5W solution between pulses of glue injection ("sandwich technique"). This reduces the risk of microcatheter retention and allows for control of the amount and depth of penetration of n-BCA [36].

Advantages of this technique include short time to embolization, low rate of same-vessel recanalization, and the ability to penetrate vascular beds in a flow-directed fashion. Complications of its use include pulmonary embolism, catheter retention, formation of a glue mass that can be a 
source of infection, tissue erosion, muscle dysfunction, transient local pain with erythema and swelling due to the inflammatory reaction after the procedure [37].

There are limited reports in the literature describing its use in peripheral AVMs. Nevertheless n-BCA has been mostly used for embolization of cerebral AVMs [38]. The largest series has been reported by Kitagawa et al. with 23 patients and 29 embolizations using nBCA and lipiodol where the aim of the embolization was slowing down the flow to perform a polidocanol sclerotherapy after the treatment. The rate of effective results was $87 \%$, with $9 \%$ complete remission and $78 \%$ partial remission. No major complications occurred but 2 localized arterial thromboses and non-healing skin ulcers were seen in 2 patients [37].

\subsubsection{Polyvinyl alcohol (Onyx)}

"Onyx" is an ethylene vinyl alcohol copolymer (EVOH) mixed with a solvent (dimethyl sulfoxide or DMSO). Polymer precipitation occurs once it comes in contact with an aqueous solution. The solvent diffuses out, leaving a polymeric solid outer cast around the tip of the microcatheter acting as a backstop to allow the mixture to be pushed into the AVM ("plug and go" technique).

The benefits of Onyx compared with n-butyl cyanoacrylate are that it is not an adhesive agent and thus, it can be injected over a long period of time, allowing for complete nidal penetrance without risk of catheter adherence. The use of detachable tip microcatheters allows greater reflux and longer injection time. Onyx can also be injected using a direct percutaneous access needle (DMSO compatible). Some of the downsides of Onyx are its expensive cost, increased use of continuous fluoroscopy, and significant post-intervention artifact seen on CT imaging. Onyx contain suspended micronized tantalum powder for visualization under fluoroscopy. This results in a black vessel cast, which may lead to skin discoloration. Complications of its use include pulmonary embolism, catheter retention, nerve injury and skin discoloration.

Reports of its use have mostly involved embolization of cerebral AVMs. There are a few small case series on its use in peripheral AVMs. Thiex et al. demonstrated effective treatment of 18 cervical-facial AVMs using Onyx (71 procedures). Transient swelling and local tenderness were seen in 7 patients but there were no serious complications or skin tattooing in their series [39].

Arat et al. used Onyx to treat 3 craniofacial AVMs with total removal in 2 cases (one combined with surgery and another small one with onyx alone). In both, the complication was retention of the catheter tip. The third case had residual AVMs and refused more embolization sessions. One patient had skin discoloration [40].

Giurazza et al. recently reported a series of 16 patients, with a total of 38 procedures of transarterial embolization of peripheral high-flow AVM with Onyx. A technical success was obtained in 11 patients; at 30-day of follow-up, 15 patients showed improvements in symptoms, even those with incomplete embolization; however, after almost 1 year from treatment accomplishment, 7 patients (44\%) showed relapse of symptoms and presented with radiological signs of AVM recurrence. No clinically relevant complications occurred [41].

Dabus et al. treated 12 patients with symptomatic peripheral AVMs with Onyx. A complete occlusion was obtained in $50 \%$ of the patients and the other $50 \%$ showed a mild residual AVM on arteriography within a mean follow-up period of 10 months. One episode of skin ulceration was seen [27].

Meila et al. reported that prolonged and repeated Onyx injections within the same AVM pedicle are possible and allow it to be pushed more distally toward and within the nidus [28].

\subsubsection{Precipitation hydrophobic injectable liquid (PHIL)}

Precipitation hydrophobic injectable liquid polylactide-coglycolide and plyhydroxyethylmethacrylate (PHIL) is a novel liquid embolic agent used in fistulas and AVMs. PHIL, like Onyx consists of an EVOH copolymer dissolved in DMSO, but for fluoroscopy purposes it has an iodine component covalently bonded to the EVOH copolymer instead of suspended micronized tantalum powder. Therefore, PHIL is white instead of black, while preserving other properties of EVOH copolymers such as its softer consistency after precipitation. Furthermore, the absence of a metallic component leads to a more homogenic radiodensity during embolization, reduces artifacts at follow-up imaging and should reduce the risk of microcatheter blockage.

Veld reported the use of PHIL on the management of a small auricular AVM fed by branches of the external carotid artery. After the nidus was filled with embolic agent, the AVM did not decrease in size, which may be considered a cosmetic downside of this technique. However, skin color reverted to normal improving its cosmetically appealing characteristics. Veld described the reduced skin discolouration as an advantage of this agent [42].

\subsubsection{Fibrin glue}

Fibrin Glue (Tisseal) is a liquid fibrin sealant composed of human fibrinogen, plasma, and thrombin. It is typically used for surgical hemostasis or tissue sealing. However, Chen et al. used fibrin glue combined with OK-432 (picibanil) and pingyangmycin in 18 AVMs of the face and neck and reported good outcomes. Twelve lesions (67\%) completely involuted, 4 (22\%) mostly and $2(11 \%)$ partially involuted. The follow-up period ranged from 6 to 12 months. None of the patients presented with hematologic toxic effects or signs of pulmonary involvement [43].

One of the risks of glues and liquid fibrin injection is that the delivery of the agent is not well controlled, and non-target vessels may be at risk for embolization. De Luca et al. described a "glue lung" in a boy with a complex Galen vein arteriovenous malformation. During the angiographic procedure, some of the colloidal glue suddenly embolized into the pulmonary vascular bed [44].

\subsubsection{Polyvinyl alcohol particles (PVA)}

Polyvinyl Alcohol Particles are made from a polyvinyl alcohol foam sheet that is vacuum dried and rasped into particles. They provide permanent occlusion by adherence to the 
vessel. The results are an inflammatory reaction and focal angionecrosis, with vessel fibrosis developing over time.

The major disadvantage of PVA particles is their tendency to aggregate, occluding vessels more proximally than might be expected based on stated size. Particle clumping can cause catheter occlusion and they can also accumulate in the catheter hub and theoretically cause subsequent nontarget embolization when the catheter is flushed [45].

In a retrospective review 10 patients with extensive cervicofacial AVMs were treated only with PVA embolization. Residual or recurrent disease required revision surgery in 8 patients [17]. Bhandari treated 14 patients with facial AVMs using PVA. In $90-100 \%$ of the cases devascularisation was achieved and the lesions were resected 24-48 $\mathrm{h}$ after the embolisation. There were no embolisation-related complications with polyvinyl alcohol and no recurrence in 6 months [46].

\section{Conclusions}

AVMs should be differentiated from other vascular lesions such as hemangiomas based on their clinical and radiological features. AVMs can be considered focal or diffuse and classification systems are available both to describe their growth pattern and angiographic appearance. These classifications are useful not only for comparing results between centers but as an aid to select individualized therapy and prognosis.

Different therapies have been reported for head and neck AVMs in the literature. However, there is a limited amount of studies evaluating its efficacy and therefore, there are no globally agreed guidelines.

In small isolated AVMs with a clearly defined feeding vessel and without bony involvement, surgical monotherapy may be the first option for primary treatment. For more extensive lesions or previously treated AVMs the combination of superselective embolization and surgery leads to better intraoperative management and results in the highest success rates. However, recurrence after embolization or resection is reported in up to $80 \%$ of cases [10]. Incomplete resection and embolization can induce aggressive growth of the remaining nidus and the risk of progression is up to $50 \%$ within the first 5 years $[8,20,28,29]$. Recurrences can occur up to 10 years later and thus, a long-term post-treatment follow-up is recommended to detect recurrence [17]. Therefore, an interdisciplinary treatment approach is crucial in making decisions about the best therapeutic approach and achieving optimal outcome.

\section{Declaration of Competing Interest}

The authors report no conflicts of interest.

\section{References}

[1] Mulliken JB, Glowacki J. Classification of pediatric vascular lesions. Plast Reconstr Surg 1982;70:120-1.

[2] Eivazi B, Werner JA. Management of vascular malformations and hemangiomas of the head and neck: an update. Curr Opin Otolaryngol Head Neck Surg 2013;21:157-63.
[3] Rosenberg TL, Suen JY, Richter GT. Arteriovenous malformations of the head and neck. Otolaryngol Clin N Am 2018;51:185-95.

[4] Cariati P, Marin-Fernandez AB, Julia-Martinez MA, Perez-de PercevalTara M, Sanchez-Lopez D, Martínez-Lara I. Endovascular treatment of an intraosseous arteriovenous malformation of the mandible in a child. A case report. J Clin Exp Dent 2018;10:189-91.

[5] Richter GT, Suen JY. Pediatric extracranial arteriovenous malformations. Curr Opin Otolaryngol Head Neck Surg 2011;19:455-61.

[6] Stapf C, Mohr JP, Pile-Spellman J, Solomon RA, Sacco RL, Connolly ES. Epidemiology and natural history of arteriovenous malformations. Neurosurg Focus 2001;11:1-5.

[7] Kumar A, Mittal M, Srivastava D, Jaetli V, Chaudhary S. Arteriovenous malformation of face. Contemp Clin Dent 2017;8:482-4.

[8] Kansy K, Bodem J, Engel M, Freudlsperger C, Mohlenbruch MA, Herweh $\mathrm{C}$, et al. Interdisciplinary treatment algorithm for facial high-flow arteriovenous malformations, and review of the literature. J Craniomaxillofac Surg 2018;46:765-72.

[9] Visser A, FitzJohn T, Tan ST. Surgical management of arteriovenous malformation. J Plast Reconstr Aesthet Surg 2011;64:283-91.

[10] Uller W, Alomari AI, Richter GT. Arteriovenous malformations. Semin Pediatr Surg 2014;23:203-7.

[11] Kim SH, Han SH, Song Y, Park CS, Song JJ. Arteriovenous malformation of the external ear: a clinical assessment with a scoping review of the literature. Braz J Otorhinolaryngol 2017;83:683-90.

[12] Kim JB, Lee JW, Choi KY, Yang JD, Cho BC, Lee SJ, et al. Clinical characteristics of arteriovenous malformations of the head and neck. Dermatol Surg 2017;43:526-33.

[13] Spreafico R, Sordo L, Bellotto R, Schipano M, Rescaldani A, Parmigiani F. Arterio-venous malformation of the mandible. Case report and review of the literature. Acta Otorhinolaryngol Ital 2016;36:333-6.

[14] Fowell C, Jones RT, Nishikawa H, Monaghand A. Arteriovenous malformations of the head and neck: current concepts in management. $\mathrm{Br}$ J Oral Maxillofac Surg 2016;54:482-7.

[15] Liu A, Mulliken JB, Zurakowski B, Fishman SJ, Greene AK. Extracranial arteriovenous malformations: natural progression and recurrence after treatment. Plast Reconstr Surg 2010;125:1185-94.

[16] Kohout MP, Hansen M, Pribaz JJ, Mulliken JB. Arteriovenous malformations of the head and neck: natural history and management. Plast Reconstr Surg 1998;102:643-54.

[17] Ritcher GT, Suen JY. Clinical course of arteriovenous malformations of the head and neck: a case series. Otolaryngol Head Neck Surg 2010;142:184-90.

[18] Gemmete JJ, Pandey AS, Kasten SJ, Chaudary N. Endovascular methods for the treatment of vascular anomalies. Neuroimag Clin N Am 2013;23:703-28.

[19] Vaisnyte B, Vajauskas D, Palionis D, Misonis N, Kurminas M, Nevidomskyte D, et al. Diagnostic methods, treatment modalities and follow-up of extracranial arteriovenous malformations. Medicina (Kaunas) 2012;48:388-98.

[20] Richter GT, Friedman AB. Hemangiomas and vascular malformations: current theory and management. Int J Pediatr 2012;2012:645-78.

[21] de Miguel R, Lopez-Gutierrez JC, Boixeda P. Arteriovenous malformations: a diagnostic and therapeutic challenge. Actas Dermosifiliogr 2014;105(4):347-58.

[22] Wei T, Zhang H, Cetin N, Miller E, Moak T, Suen JY, et al. Elevated expression of matrix metalloproteinase-9 not matrix metalloproteinase-2 contributes to progression of extracranial arteriovenous malformation. Sci Rep 2016;6:1-12.

[23] Carqueja IM, Sousa J, Mansilha A. Vascular malformations: classification, diagnosis and treatment. Int Angiol. 2018;37:127-42.

[24] Steinklein JM, Shatzkes DR. Imaging of vascular lesions of the head and neck. Otolaryngol Clin North Am. 2018;51(1):55-76.

[25] Yamamoto Y, Ohura T, Minakawa H, Sugihara T, Yoshida T, Nohira K, et al. Experience with arteriovenous-malformations treated with flap coverage. Plast Reconstr Surg 1994;94(3):476-82.

[26] Cho S, Do YS, Shin SW, Kim DY, Kim YW, Park KB, et al. Arteriovenous malformations of the body and extremities: analysis of therapeutic outcomes and approaches according to a modified angiographic classification. J Endovasc Ther 2006;13:527-38. 
[27] Dabus G, Linfante I, Benenati J, Perlyn CA, Martinez-Galdamez M. Interventional management of high-flow craniofacial vascular malformations: a database analysis and review of the literature. J Neurointerv Surg 2017;9:92-6.

[28] Meila D, Grieb D, Greling B, Melber K, Jacobs C, Hechtner M, et al. Endovascular treatment of head and neck arteriovenous malformations: long-term angiographic and quality of life results. J Neuronterv Surg 2017;9:860-6.

[29] Le Fourn E, Herbreteau D, Papagiannaki C, Lorette G, Sirinelli D, Goga D, et al. Efficacy and safety of embolization in arteriovenous malformations of the extremities and head and neck: a retrospective study of 32 cases. Eur J Dermatol 2015;25:52-6.

[30] Case D, Folzenlogen Z, Rochon P, Kumpe D, Roark C, Seinfield J. Embolization of head and neck vascular malformations using serial arterial embolization followed by dominant arterial embolization with two microcatheter technique. J Vasc Interv Neurol 2018;10:47-51.

[31] Mason KP, Michna E, Zurakowski D, Koka BV, Burrows PE. Serum ethanol levels in children and adults after ethanol embolization or sclerotherapy for vascular anomalies. Radiology 2000;217:127-32.

[32] Shin BS, Do YS, Lee BB, Kim DI, Chung IS, Cho HS, et al. Multistage ethanol sclerotherapy of soft-tissue arteriovenous malformations: effect on pulmonary arterial pressure. Radiology 2005;235:1072-7.

[33] Su L, Wang D, Han Y, Wang Z, Zheng L, Fan X. Absolute ethanol embolization of infiltrating-diffuse extracranial arteriovenous malformations in the head and neck. Eur J Vasc Endovasc Surg 2015;50:114-21.

[34] Park KB, Do YS, Kim DI, Kim YW, Shin BS, Park HS, et al. Predictive factors for response of peripheral arteriovenous malformations to embolization therapy: analysis of clinical data and imaging. J Vasc Interv Radiol 2012;23:1478-86.

[35] Do YS, Park KB, Park HS, Cho SK, Shin SW, Moon JW, et al. Extremity arteriovenous malformations involving the bone: therapeutic outcomes of etanol embolotherapy. J Vasc Interv Radiol 2010;21:807-16.

[36] Rosen RJ, Contractor S. The use of cyanoacrylate adhesives in the management of congenital vascular malformations. Semin Intervent Radiol 2004;21:59-66.
[37] Kitagawa A, Yamamoto T, Matsunaga N, Yamaji M, Ikeda S, Izumi Y, et al. Polidocanol sclerotherapy combined with transarterial embolization using n-butyl cyanoacrylate for extracranial arteriovenous malformations. Cardiovasc Intervent Radiol 2018;41:856-66.

[38] Pollak JS, White RI. The use of cyanoacrylate adhesives in peripheral embolization. J Vasc Interv Radiol 2001;12:907-13.

[39] Thiex R, Wu I, Mulliken JB, Greene AK, Rahbar R, Orbach DB. Safety and clinical efficacy of Onyx for embolization of extracranial head and neck vascular anomalies. Am J Neuroradiol 2011;32:1082-6.

[40] Arat A, Cil BE, Vargel I, Turkbey B, Canyigit M, Peynircioglu B, et al. Embolization of high-flow craniofacial vascular malformations with onyx. AJNR Am J Neuroradiol 2007;28:1409-14.

[41] Giurazza F, Corvino F, Cangiano G, Cavaglia E, Amodio F, Silvestre M, et al. Transarterial embolization of peripheral high-flow arteriovenous malformation with ethylene vinyl alcohol copolymer (Onyx): singlecenter 10-year experience. Radiol Med 2019;124:154-62.

[42] In 't Veld M, Willems PW. Absence of skin discoloration after transarterial embolization of a subcutaneous auricular arteriovenous malformation with phil. Intervent Neuroradiol 2016;22(5):606-10.

[43] Chen W, Huang Z, Zhang D, Chai Q. Percutaneous sclerotherapy of massive venous malformations of the face and neck using fibrin glue combined with OK-432 and pingyangmycin. Head Neck 2010;32:467-72.

[44] De Luca D, Piastra M, Pietrini D, Rollo M, Conti G. "Glue lung": pulmonary micro-embolism caused by the glue used during interventional radiology. Arch Dis Child 2008;93:263.

[45] Vaidya S, Tozer KR, Chen J. An overview of embolic agents. Semin Intervent Radiol 2008;25(3):204-15.

[46] Bhandari PS, Sadhotra LP, Bhargava P, Bath AS, Mukherjee MK, Maurya $S$. Management strategy for facial arteriovenous malformations. Indian J Plast Surg 2008;41(2):183-9. 